\title{
Vegetative propagation of Freesia through callus cultures
}

\author{
Y. P. S. Bajaj ${ }^{1}$ and R. L. M. Pierik \\ Department of Horticulture'2, Agriculture University, Wageningen, the Netherlands
}

Accepted: 12 August 1974

\begin{abstract}
Summary
Isolated segments of corm, stem, leaves, flower-buds and anthers from flowering Freesia cv. 'Ballerina' plants have been induced to form callus on a modified Murashige and Skoog's medium supplemented with NAA and PBA. The best callus was obtained from young flower-buds kept at $25^{\circ} \mathrm{C}$ in darkness. Callus could be subcultured in darkness on a medium containing auxin and cytokinin. Complete plantlets were obtained by transferring the callus to light on an auxin-free medium containing kinetin or PBA. Plantlets have also been regenerated from young anthers.

Adventitious organ formation in explants and callus was strongly determined by the auxin/cytokinin ratio in the medium. Generally, auxins promoted rooting, whereas cytokinins enhanced budding. Light, in comparison to darkness promoted both root and bud formation while at the same time callus growth was retarded. The potential of vegetative propagation of Freesia by callus in culture in flower industry is discussed.
\end{abstract}

\section{Introduction}

Freesias are normally propagated vegetatively by means of corms. The number of daughter corms produced by one mother corm in one year is very small $(3-6)$. When a breeder has obtained a new cultivar, it takes $8-10$ years before he is able to produce a clone which is large enough for commercial purposes. Because of the immense commercial interest of the flower industry in this plant species, it is highly desirable to develop methods which enable us to speed up the rate of multiplication, particularly in the first two years. By using tissue culture technique the time required for the release of a new cultivar for general commercial use can be enormously reduced. In annual reports of the John Innes Intitute, (Davies \& Griffiths 1971; Davies \& Helsop 1972; Hussey \& Wyvill, 1972) mention is made about the in vitro propagation of Freesia. However, these abstracts are very vague and do not give any indication whatsoever about the exact medium and the precise conditions required for the induction of callus, its subculture and differentiation; with the result it is impossible to reproduce their work from the information given.

For the reasons mentioned above we started to develop a method which is dependable for commercial purposes. In this communication main emphasis is given upon

1 Present address: Institut für Pflanzenphysiologie und Zellbiologie, Freie Universität Berlin, D-1 Berlin 33 (Dahlem), Germany.

2 Publication 404. 
callus induction and callus subculture, although the regeneration phenomenon in various explants and anthers is also described.

\section{Material and methods}

The material for the experimental study was obtained from flowering plants of Freesia cv. 'Ballerina', which were obtained from the Glasshouse Crops Research and Experiment Station at Naaldwijk. Initially, for a general survey of callus induction, explants of corm, stem, leaves, pedicel, flower-buds and anthers were cultured. However, subsequently only young flower-buds were used. Explants were sterilized by first immersing them in $70 \%$ ethanol for a few seconds, and then treating them with $1 \%$ $\mathrm{NaOCl}$ for 20 minutes. These explants ware rinsed three times with sterile tap water, and then cultured with their basal ends in the medium. Unless stated otherwise, cultures were kept at $25^{\circ} \mathrm{C}$ in darkness. To promote organ formation and development in explants and callus tissue, the cultures were transferred from darkness to continuous fluorescent light (Philips TL 4OW/57) at $23^{\circ} \mathrm{C}$.

The basic medium contained all the components of the MS medium (Murashige \& Skoog, 1962), except indoleacetic acid and kinetin, while Edamin was replaced by casein hydrolysate $(500 \mathrm{mg} / \mathrm{l})$. The medium was adjusted to $\mathrm{pH} 5.8$ before autoclaving, and was solidified with $0.8 \%$ Difco Bacto agar. Of the medium $15 \mathrm{ml}$ were poured into pyrex glass tubes and autoclaved at $112^{\circ} \mathrm{C}\left(0.6 \mathrm{~kg} / \mathrm{cm}^{2}\right)$ for 20 minutes. To obtain optimum growth, the medium was supplemented with various combinations and concentrations of indoleacetic acid (IAA), naphtaleneacetic acid (NAA), indolebutyric acid (IBA), 2,4-dichlorophenoxyacetic acid (2,4-D), 6-benzylamino purine (BA), kinetin, 6-(benzylamino)-9-(2-tetrahydropyranyl)-9H-purine (PBA or SD 8339), casein hydrolysate $(\mathrm{CH})$ and coconut milk. The choice of MS medium and the frequent use of the cytokinin PBA was based on our experience with another monocotyledon, Anthurium andraeanum (Pierik et al., 1974).

\section{Results and discussion}

\section{Callus induction}

Initially, experiments were conducted on explants taken from Freesia plants at various stages of development i.e. stage 1: flower-buds just visible, poor stem elongation; stage 2: flower buds small, still enclosed, stem elongated; stage 3: first flower-buds just opened, stem considerably elongated; stage 4: plants with completely opened flowers. Explants (about 1-cm segments) from corm, stem, leaf, pedicel, and flowerbuds and anthers were cultured on basic medium with combinations of several growth regulators, and the cultures maintained at $25^{\circ} \mathrm{C}$ both in light and darkness. The results of these preliminary experiments are shown in Fig. 1. Adventitious root formation was strongly enhanced by light as compared to darkness, and also by a relative high auxin/ cytokinin ratio in the medium; root primordia started to appear after 3-4 weeks. The combination of NAA $(5 \mathrm{mg} / \mathrm{l})$ and PBA $(2 \mathrm{mg} / \mathrm{l})$ was effective for callus induction. We observed that in principle all types of explants were capable of forming callus and had the capacity to regenerate (Fig. 1), but optimum callus induction was invariably obtained from young flower-buds. The flower-buds reacted uniformly and nearly $100 \%$ of them yielded callus. The developmental stage of the parent plant was also of 


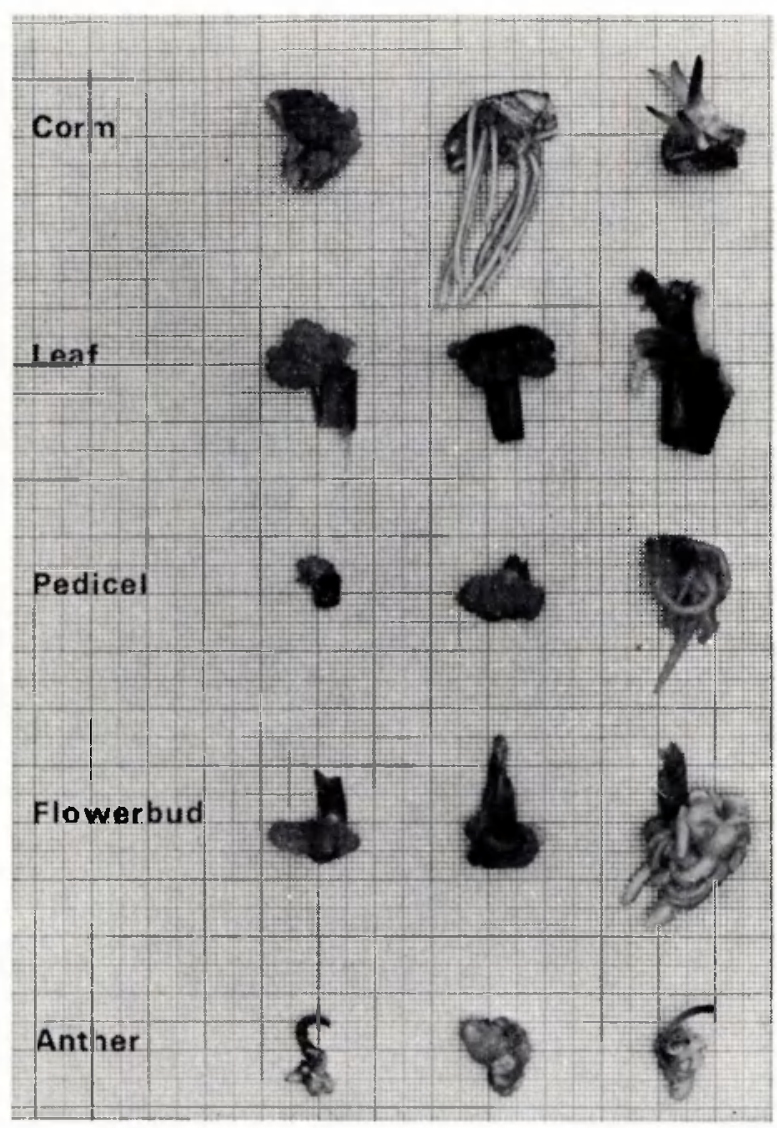

Fig. 1. Explants from various parts and/or to undergo organogenesis of Freesia are capable to form callus (root and bud formation).

importance, the flower-buds from stage 2 reacted favourably.

The next set of experiments with young flower-buds cultured in darkness and with NAA $(5 \mathrm{mg} / \mathrm{l})$ and PBA $(2 \mathrm{mg} / \mathrm{l})$ in the basic medium gave the following results. Addition of macroelements of Murashige \& Skoog (1962) resulted in much better callus induction than Heller's (Heller, 1953) or Knop's (Knop, 1884) macroelements. The addition of glucose or sucrose was essential, $3 \%$ being slightly better than $2 \%$; however no significant difference in callus formation by glucose or sucrose was noticed. The most rapid callus formation took place at $25^{\circ} \mathrm{C}$ in comparison to lower temperatures $\left(17\right.$ and $21^{\circ} \mathrm{C}$ ), although at $21^{\circ} \mathrm{C}$ good callus was obtained. The subsequent experiments were, therefore, continued on the MS medium and the cultures maintained at $25^{\circ} \mathrm{C}$.

In our preliminary experiments, the role of auxin and cytokinin appeared to be essential, so a comparison was made of various cytokinins (BA, PBA and kinetin) alone or in combination with various auxins (NAA, IBA and IAA). The combination of PBA with NAA appeared to be the best for callus induction. It was shown that PBA at $2 \mathrm{mg} / \mathrm{l}$ only induced parthenocarpic fruit development and no callus (Fig. 2, upper row). When PBA $(2 \mathrm{mg} / \mathrm{l})$ was combined with NAA, optimum callus growth 


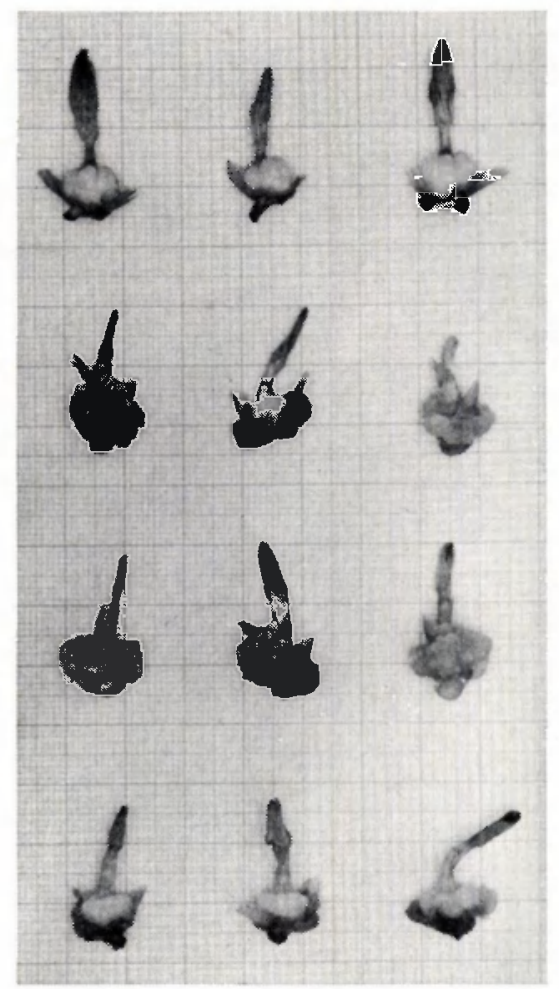

Fig. 2. Effect of various concentrations of NAA on in vitro cultivated young flower-buds, grown on the basic medium containing PBA $(2 \mathrm{mg} /)$ ). The first row (without auxin) shows the parthenocarpic development of fruits. $\mathrm{NAA}$ at $5 \mathrm{mg} / \mathrm{l}$ and $10 \mathrm{mg} / \mathrm{l}$ (second and third row from above) induced callus, while at $50 \mathrm{mg} / 1 \mathrm{NAA}$ callus induction was inhibited (fourth row from above).

occurred with NAA at 5 or $10 \mathrm{mg} / 1$ (Fig. 2, second and third row), but callus induction was decreased when NAA was raised to $50 \mathrm{mg} / \mathrm{l}$ (Fig. 2, fourth row).

In the next experiment the combination of NAA $(0,0.1,1.0$ or $5 \mathrm{mg} / 1)$ and PBA $(0$, $1.0,5.0$ or $10 \mathrm{mg} / \mathrm{l})$ was further examined. This experiment showed that NAA $(5 \mathrm{mg} / \mathrm{l})$ + PBA (5 mg/l) or NAA $(5 \mathrm{mg} / 1)+$ PBA $(10 \mathrm{mg} / 1)$ induced excellent callus on flower-buds, although NAA $(1 \mathrm{mg} / \mathrm{l})+$ PBA $(5 \mathrm{mg} / \mathrm{l})$ or NAA $(1 \mathrm{mg} / \mathrm{l})+$ PBA $(10$ $\mathrm{mg} / \mathrm{l})$ were quite comparable. It should, however, be noted that there is no absolute cytokinin requirement for callus induction, although auxin is indispensable. When auxin and cytokinin are combined in the ratios mentioned above, during the first 5 weeks of culture a mass of callus is produced.

Organ formation during callus induction

Although the primary purpose of this study was to obtain callus, in numerous explants there was a simultaneous induction of callus and organ differentiation. Generally, root and bud formation were promoted by light, and inhibited partially or completely by darkness. The level of auxin-cytokinin in the medium appeared to be very essential for organ differentiation. As can be seen in Fig. 1, all types of explants and organs are capable of producing callus, roots and shoots. Rooting was promoted by increasing the auxin level, and decreased by raising the cytokinin level. The most effective cytokinin for sprout regeneration was PBA, followed by BA and kinetin. 


\section{Anther culture}

Anthers taken from flowers at various stages of development were cultured on MS medium supplemented with various growth regulators (see legends of Fig. 3). The anthers and the stamens (Fig. 3A) obtained from opened flowers readily formed roots (Fig. 3B-D). These roots originated either from the basal end of the filament (Fig. 3B), or from the junction of filament and the anther. Relatively young anthers taken from flower-buds behaved in a different way altogether. They had a tendency to proliferate to form a mass of callus. This callus was initiated either (a) from the basal end of the anther (Fig. 3E), or (b) by bursting of the anther (Fig. 3F). The callus obtained by bursting was compact with small cells as compared to the one coming from the basal part of the anther. It is assumed that the callus originating by bursting of the anther is haploid. Although no detailed observations on pollen were made, occasionally ab-

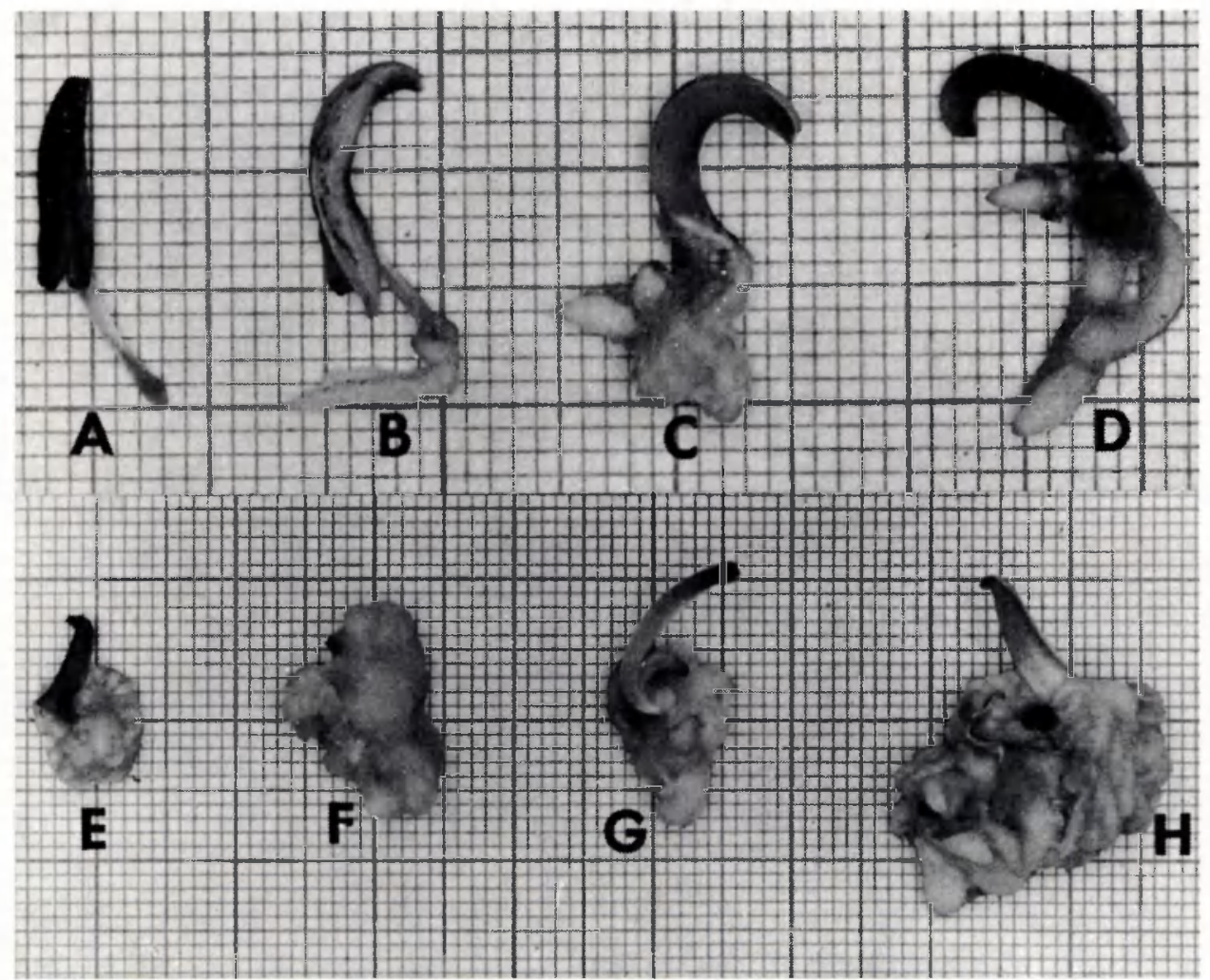

Fig. 3. A-D: Rhizogenesis in anthers obtained from opened flowers cultured on a basic medium containing $2,4-\mathrm{D}(0.2 \mathrm{mg} / \mathrm{l})+\mathrm{NAA}(0.2 \mathrm{mg} / \mathrm{l})+\operatorname{kinetin}(2 \mathrm{mg} / \mathrm{l})$ and coconut milk (10\%). E-F: (6-week old cultures of young anthers on basic medium supplemented with 2,4-D (2 mg/l) + kinetin $(2 \mathrm{mg} / \mathrm{l})+$ coconut milk (10\%); note the proliferation at the basal end of the anther (E), and an all round callusing by bursting of the anther (F). G-H: 8-week and 12-week old cultures of young anthers on basic medium containing NAA $(0.5 \mathrm{mg} / \mathrm{l})+$ PBA $(2 \mathrm{mg} / \mathrm{l})+$ kinetin $(1 \mathrm{mg} / \mathrm{l})+$ casein hydrolysate $(500 \mathrm{mg} / \mathrm{l})$ showing the differentiation of shoots and roots. 
normally large pollen with four nuclei were observed. It seems probable that such pollen are the source of haploid callus shoots (Fig. 3G). The proliferating anthers on MS medium containing NAA $(0.5 \mathrm{mg} / \mathrm{l})+\mathrm{PBA}(2 \mathrm{mg} / \mathrm{l})+\operatorname{kinetin}(1 \mathrm{mg} / \mathrm{l})+\mathrm{CH}$ $(500 \mathrm{mg} / \mathrm{l})$ differentiated to form shoots (Fig. 3G, H) which eventually developed into plants.

\section{Callus subculture and organ differentiation}

As already mentioned, the induction of callus and its subsequent growth was better in darkness than in light, the same was true for the subcultured callus as well. Callus obtained from the flower-buds could be subcultured 5 weeks after initiation, however, when subculture was delayed, the callus had a tendency to gradually loose its quality and turned brownish. The growth of subcultured Freesia callus is slow.

Several combinations of auxins-cytokinins were tested to find a suitable medium for subculture. Good growth has been obtained on the basic medium containing IAA $(2 \mathrm{mg} / \mathrm{l})$ and kinetin $(4 \mathrm{mg} / \mathrm{l})$; however, on this medium root initiation could not yet be completely inhibited, as Freesia seems to have an enormous capacity to regenerate roots. The best callus growth up till now was obtained on the basic medium with NAA $(0.1 \mathrm{mg} / \mathrm{l})$ and PBA $(5 \mathrm{mg} / \mathrm{l})$; on this medium organ regeneration was very poor.

The callus subcultured for two months in darkness on a basic medium with $5 \mathrm{mg} / \mathrm{l}$ of kinetin when transferred to light, differentiated roots and shoots and eventually developed into complete plantlets after next two months (Fig. 4). These results were also obtained when kinetin was replaced by PBA $(5 \mathrm{mg} / \mathrm{l})$, although PBA has a stronger capacity to inhibit rooting as compared with kinetin. It seems that light and cytokinin play a very important role in the induction of organogenesis in Freesia.

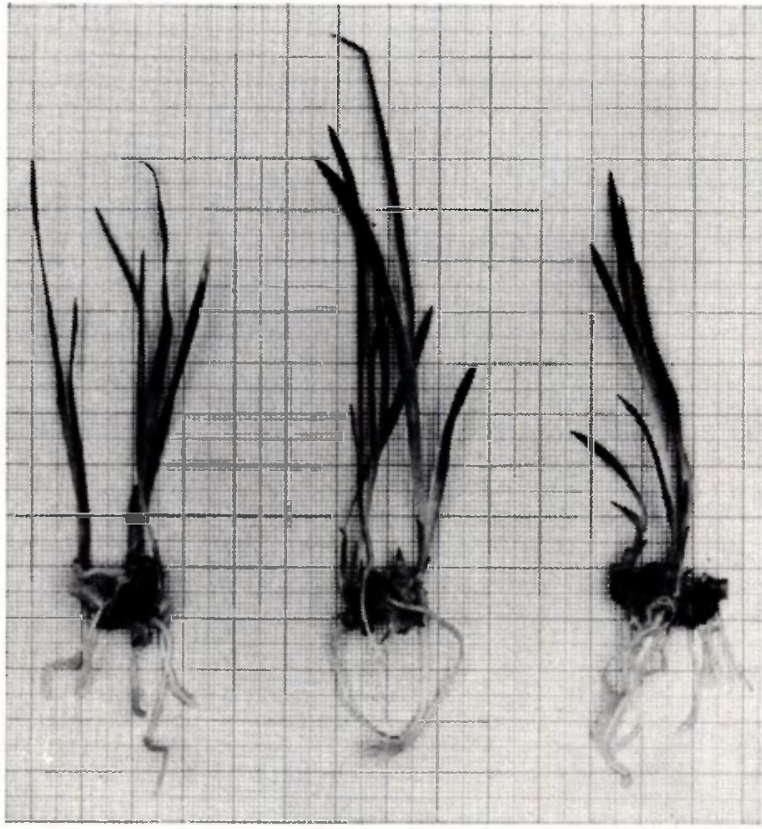

Fig. 4. Complete plantlets of Freesia obtained from callus tissue subcultured on basic medium + kinetin $(5 \mathrm{mg} / \mathrm{l})$ for 4 months. The cultures were maintained in darkness for first two months, and subsequently transferred to light for the next two months. 


\section{Conclusions}

To conclude, the foregoing experiments have very clearly demonstrated that Freesia has tremendous capacity to regenerate under in vitro conditions. The callus can be successfully induced, subcultured, and can further be manipulated to undergo morphogenesis and to form plants. If callus culture is employed on a large scale as a means of vegetative multiplication, it will be of great economical value for the flower industry, as it will drastically reduce the time required for the introduction and propagation of the desirable cultivars. At present it is not yet known whether the in vitro system developed for the cv. 'Ballerina' is also applicable to other cultivars. An essential step will also be to examine the established callus clones cytologically and to make a critical comparison between the original genotype and the clones produced in vitro.

\section{Acknowledgments}

The authors are grateful to Ir T. Dijkhuizen of the Glasshouse Crops Research and Experiments Station Naaldwijk, for providing the Freesia plants. Appreciation is also expressed to Miss Tiny Steegmans and Mr Wim van Schaik for their skilful technical assistance. The free gift of PBA (SD 8339) by Shell International Research, The Hague, is gratefully acknowledged. The stay of Dr Y. P. S. Bajaj was made possible by a research fellowship granted by the Agricultural University of Wageningen, the Netherlands.

\section{References}

Davies, D. R. \& P. Griffiths, 1971. In vitro propagation of Freesia. A. Rep. John Innes Inst. $62: 45$. Davies, D. R. \& P. Helsop, 1972. In vitro propagation of Freesia. A. Rep. John Innes Inst. 63: 64.

Heller, R., 1953. Recherches sur la nutrition minérale des tissues végétaux cultivés in vitro. Ann. Sci. nat. Bot. Biol. Vég. 14: 1-223.

Hussey, G. \& C. Wyvill, 1972. Propagation of bulbous species by tissue culture. A. Rep. John Innes Inst. 63: 64-66.

Knop, W., 1884. Bereitung einer konzentrierter Nährstofflösung für Pflanzen. Landw. VersStn. 30: 292-294.

Murashige, T. \& F. Skoog, 1962. A revised medium for rapid growth and bio-assays with tobacco tissue cultures. Physiol. Plant 15: 473-497.

Pierik, R. L. M., Steegmans, H. H. M. \& J. A. J. van der Meys, 1974, Plantlet formation in callus tissues of Anthurium andraeanum Lind. Scient. Hort. 2: 193-198. 